\title{
DAVE COGHILL
}

opinion \& debate

\section{Attention-deficit hyperactivity disorder: should we believe the mass media or peer-reviewed literature? ${ }^{\dagger}$}

Bailly's review describes the author's perspectives on the 'intense controversies' surrounding attention-deficit hyperactivity disorder (ADHD) and its treatment with stimulant medications. Drawing on a range of literature sources, including the UK press, pharmaceutical industry websites and peer-reviewed scientific papers, he questions the validity of ADHD as a concept and disorder, the accuracy and reliability of diagnosis, the use of stimulant medications and the impact of advertising by the pharmaceutical industry. There are, however, additional sources and alternative interpretations.

\section{The validity and reliability of ADHD as a diagnostic entity}

Robins and Guze (1970) proposed criteria to assess the evidence on the validity of psychiatric disorders. They suggest that such validity derives not from any single study but from a pattern of consistent data across a range of areas, including clinical correlates, family history, treatment response, laboratory studies, course and outcome. The evidence supporting ADHD, as defined by DSM-IV (American Psychiatric Association, 1994), and hyperkinetic disorder, a narrower concept defined by ICD-10 (World Health Organization, 1993) (collectively referred to as ADHD throughout this article), fulfilling these criteria is extensive and has been comprehensively reviewed on many occasions and will not be discussed in detail for reasons of brevity (see for example Schachar \& Tannock, 2002). Both DSM-IV and ICD-10 require the presence of severe, persistent and pervasive, and levels of inattentive, overactive and impulsive, behaviours with onset early in life (by definition before the age of 7 years, nearly always before the age of 5 years and frequently earlier). Of key importance in both systems is the requirement for the presence of clinically significant impairment in addition to the operationally defined symptoms and their associations. The Children's Global Assessment Scale (CGAS) (Shaffer et al., 1983) is a helpful instrument for measuring impairment and was influential in the definition of DSM-IV ADHD, where a cut-off point of 60 on the CGAS - indicating a level of clinical impairment that requires treatment - was used to define the number of symptom criteria for ADHD. Field trials found that five symptoms of ADHD had to be present in order to arrive at the CGAS cut-off point of 60 (Lahey et al, 1994). In order to be conservative and avoid falsepositives the standard was set at six or more symptoms of inattention and hyperactivity-impulsivity.

The importance of the identification, assessment and accurate diagnosis of those with ADHD should not be underestimated as, when unrecognised and untreated, severe hyperactivity, impulsivity and inattentiveness are strongly predictive of negative outcomes across a range of dimensions, including poor self-esteem, academic achievement and occupational status, peer relationships and family functioning and increased rates of accidents, disruptive and antisocial behaviour, substance misuse, mood and anxiety disorders (Fischer et al, 1990; Barkley et al, 1991; Taylor et al, 1996; Barkley et al, 2004).

Bailly is correct to point out that diagnosis must not be based merely on the presence of the required number of symptoms. The assessment of ADHD requires a careful, complete and critical, but not dismissive, examination of information from multiple sources and across a wide range of domains. The use of information from a range of sources will strengthen, rather than weaken, the assessment process. Parents and teachers are important informants as it is well recognised that they are more accurate than the child at reporting the presence of externalising (but not internalising) symptoms (Faraone et al, 1995). It is important to acknowledge that the difficulties experienced by parents and teachers in maintaining neutrality during assessment are often a consequence of having had to wait a considerable length of time and negotiate many barriers before being able to access help, and in the meantime having themselves to manage and support a challenging child. This does not make the clinician's task easier but it is not prohibitive to their conducting a full and comprehensive assessment. The striking similarities between the many published clinical guidelines on the assessment of ADHD are not serendipitous (American Academy of Child and Adolescent Psychiatry, 1997; American Academy of Pediatrics, 2001; Scottish Intercollegiate Guidelines Network, 2001; Taylor et al, 2005). Familiarity with and adherence to the recommendations made within these guidelines will assist greatly in ensuring reliability in diagnostic practice.

\section{The biological and cognitive underpinnings of ADHD}

Those who doubt or oppose the validity of ADHD as a diagnosis frequently cite statements such as that made by the National Institute for Mental Health (Kupfer et al, 2000), that 'after years of clinical research and experience with ADHD, our knowledge about the cause or causes of ADHD remain largely speculative' (p. 3). In countering this position clinical specialists and researchers in ADHD point out that these comments are being used out of context and cite the many genetic, neuroimaging, neurophysiological and neuropsychological studies which not only support the validity of the disorder but also provide strong evidence for it having a biological basis (Barkley et al, 
2002; Castellanos \& Tannock, 2002). In fact the field has reached a point at which relatively sophisticated causal theories have been proposed. Such theories emphasise problems in the inhibition of inappropriate responses (Barkley, 1998) and delay aversion (Sonuga-Barke, 2003) rather than disrupted attentional function, which although observable at a behavioural level of analysis appears intact at a cognitive level. However, we still remain some distance from demonstrating a full causal model of ADHD, or its component symptom dimensions, at multiple levels of analysis. This should come as no surprise. The brain is the most complex of biochemical machines and this, linked with the complex polygenic genetic underpinnings of ADHD, would as Gottesman and Gould (2003) describe most eloquently, 'predict a ballet choreographed interactively over time among genotype, environment, and epigenetic factors, which gives rise to a particular phenotype'. Coghill et al (2005) have recently reviewed some of the important barriers which must be overcome if we are to shift from positing causal theories to demonstrating formal causal effects. These include:

- The need for studies to work across multiple levels of analysis (e.g. genetic, neural, cognitive and behavioural) in order that the links between the elements making up causal chains can be empirically described.

- The need to recognise the existence of and then effectively model heterogeneity within ADHD samples.

- The need to integrate environmental and social mechanisms with genetic and neurobiological mechanisms in empirical designs.

- The need to properly characterise endophenotypes.

- The need to take developmental aspects seriously.

The issue of heterogeneity is particularly interesting. Until recently simple single cause models dominated the ADHD literature. Such models carry an implicit suggestion that the behavioural symptoms of $A D H D$ are a consequence of a single underlying factor and that all cases of ADHD will be similar. However there is now considerable evidence from a wide range of sources which suggests a marked heterogeneity within ADHD samples at several levels (including genetic, neural, cognitive and behavioural). This will require the development of multiple interacting developmental causal pathways in order that ADHD is fully explained (Sonuga-Barke, 2003). This heterogeneity, at a cognitive level, in part explains the difficulties in employing neuropsychological tests as part of the diagnostic process within any group of children with ADHD. Most will have some neuropsychological deficit but only a proportion will perform poorly on any one task. This has led to the recent suggestion that future classification systems should consider describing neuropsychologically rather than behaviourally defined ADHD subtypes (Nigg et al, 2005).

\section{The differential diagnosis of ADHD}

A large part of Bailly's review focuses on alternative explanations for hyperactive behaviours. Distinguishing ADHD from other treatable disorders is important, however the application of a comprehensive history and examination carried out by an experienced clinician as described above should, in most cases, enable accurate diagnoses to be made. Although sleep deprivation, hearing difficulties, bereavement and treatment with common medications such as $\beta$-stimulants can result in behavioural patterns resembling those seen in ADHD, these presentations are normally much less severe and disabling and/or temporally related to the provoking factor. Rutter and colleagues' work on the impact of the early severe deprivation experienced by children adopted from the Romanian orphanages shows a raised incidence of ADHD (among other problems), increasing as a function of length of deprivation experienced (Kreppner et al, 2001). These findings are highly suggestive of an environmental route to ADHD. However the level of deprivation suffered by these children was severe and it would be inappropriate to extend these findings to all victims of abuse. The relationship between ADHD and bipolar disorder is complex and controversial and will not be discussed in detail here (see for example Carlson, 1998). However clinicians should be wary about applying the diagnostic criteria for a manic episode to children without extreme care and consideration as to the true nature of symptoms. Finally, although parenting a child with ADHD may result in suboptimal parenting and such critical and coercive parenting styles frequently result in the child with ADHD developing a comorbid oppositional defiant disorder, there is no evidence to suggest inadequate parenting as a cause of ADHD. On the contrary, evidence from behavioural genetic studies suggests that although the heritability of ADHD is high (about 0.8 ) the contribution of shared environmental factors is very small (Faraone \& Doyle, 2000).

\section{Stimulant treatment of ADHD}

Although the precise modes of action by which the stimulant medications result in a reduction in the symptoms of ADHD remain elusive, the situation is far less pessimistic than suggested by Bailly. Considerable clinical and basic scientific study has begun to describe the complexities of stimulant actions (Solanto et al, 2001). For example Volkow et al (2001) have demonstrated that oral methylphenidate results in increased levels of extracellular dopamine. Stimulants have also been demonstrated to exert a positive, but not negative, effect on those biological and cognitive processes thought to be involved in the causation of ADHD, improving behaviour, cognitive flexibility and memory functioning (Tannock et al, 1995; Rhodes et al, 2004) rather than by 'doping them up' or turning them into 'zombies' as often suggested in the media.

Systematic reviews and meta-analyses of evidence from short-term studies have uniformly concluded that both methylphenidate and dexamfetamine are effective and safe treatments (Jadad et al, 1999). Evidence from longer-term studies, although still somewhat sparse, is starting to appear and supports continuing effectiveness and safety over the medium- to long-term (Abikoff et al, 2004). Importantly neither methylphenidate nor dexamfetamine, both of which have been used for over 50 
years to treat the symptoms of ADHD in millions of children, have been associated with serious adverse events when used as a monotherapy in either the pharmacovigilance systems or peer-reviewed journals.

Important findings have recently emerged concerning the relationships between ADHD stimulant treatment and substance misuse. For example, although the increased rates of substance misuse may largely be explained by comorbid conduct disorder, ADHD does appear to be an independent risk factor for substance misuse (Milberger et al, 1997). Stimulant treatment of ADHD reduces these increased rates by around $50 \%$ (Huss \& Lehmkuhl, 2002). Further, when taken orally methylphenidate is not associated with a drug 'high' (Volkow \& Swanson, 2003). There is some evidence (e.g from police seizures) to suggest that small quantities of methylphenidate are diverted towards illicit use, but rates of methylphenidate misuse seem to be low, with those who do choose to misuse it doing so mainly by intravenous injection.

Notwithstanding the large increases in the rates of stimulant prescribing which have been documented over recent years, the available evidence suggests there is still large regional variation in prescribing practices, and even within high prescribing areas there is a continued underrecognition and undertreatment. For example there are sevenfold differences between health boards in prescription rates for methylphenidate across Scotland (Philp et al, 2002), with high prescribing areas still falling well below the expected levels. The National Institute for Clinical Excellence (NICE), using a very conservative approach to treatment decision-making, reported that in England and Wales only 30\% of those with hyperkinetic disorder, the most severe form of ADHD, were receiving stimulant medication (National Institute for Clinical Excellence, 2000). Thus the increases in the prescription of psychostimulants over recent years represent less of a worrying 'explosion' than a move towards, but not yet to, the appropriate recognition and treatment of a serious childhood disorder

\section{The influence of the pharmaceutical industry}

Although the increased stimulant prescribing rates in the UK pre-date the recent flood of interest in ADHD by the pharmaceutical industry, it remains important to consider the potential impact of industry on clinical practice. Broadening of the ADHD concept and increasing rates of recognition, diagnosis and prescribing will all serve to increase the potential market and profits available to these companies. Advertising campaigns, sponsorship of academic meetings and other educational activities, and phase III and IV research trials must be seen as profitable exercises otherwise they would not continue to be funded. However it is important not to throw the baby out with the bath water. Extended-release stimulant preparations and novel non-stimulant treatments for ADHD potentially offer real benefits for patient care which would not have been possible without considerable investment on the part of the pharmaceutical industry.
The findings of industry-sponsored trials must be skilfully and critically appraised and interpreted with caution but they also have the potential to inform treatment decisions and occasionally advance our scientific understanding of ADHD (e.g. Swanson et al, 1999).

\section{Conclusion}

If, as a lay person, I had not been taught scientific method and critical appraisal, and my only sources of information were the popular press and the internet, then I would be confused and concerned about the validity of $A D H D$ and the use of stimulant drugs to treat it. However as a medical professional with access to an extensive peer-reviewed literature I feel able to understand the gaps in our knowledge about this complex disorder and to use an evidence-based approach to make a difference to the lives of those with ADHD.

\section{Declaration of interest}

D.C. has acted as a consultant to and received research funding from Celltech, Eli-Lilly and Janssen Cilag.

\section{References}

ABIKOFF, H., HECHTMAN, L., KLEIN, R. G., et al (2004) Symptomatic improvement in children with ADHD treated with long-term methylphenidate and multimoda psychosocial treatment. Journal of the American Academy of Child and Adolescent Psychiatry, 43, 802-811.

AMERICAN ACADEMY OF CHILD AND ADOLESCENT PSYCHIATRY (1997)

Practice parameters for the assessment and treatment of children, adolescents, and adults with attention-deficit/

hyperactivity disorder. Journal of the American Academy of Child and Adolescent Psychiatry, 36, 85S-1215.

AMERICAN ACADEMY OF PEDIATRICS (2001) Clinical practice guideline: treatment of the school-aged child with attention-deficit/hyperactivity disorder. Pediatrics, 108, 1033-1044. AMERICAN PSYCHIATRIC

ASSOCIATION (1994) Diagnostic and Statistical Manual of Mental Disorders (4th edn) (DSM-IV). Washington, DC APA.

BARKLEY, R. A. (1998) A theory of ADHD: inhibition, executive functions, self-control, and time. In AttentionDeficit Hyperactivity Disorder: A

Handbook for Diagnosis and Treatment (ed. R. A. Barkley), pp. 225-260. New York: Guilford Press.

BARKLEY, R. A., FISCHER, M., EDELBROCK, C., et al (1991) The adolescent outcome of hyperactive children diagnosed by research criteria-III. Mother-child interactions family conflicts and maternal psychopathology. Journal of Child Psychology and Psychiatry, 32, 233-255.
BARKLEY, R. A., COOK, E. H., DIAMOND, A., et al (2002) International consensus statement on ADHD January 2002. Clinical Child and Family Psychology Review, 5, 89-111.

BARKLEY, R. A., FISCHER, M., SMALLISH, L., et al (2004) Young adult follow-up of hyperactive children: antisocial activities and drug use. Journal of Child Psychology and Psychiatry, 45, 195-211.

CARLSON, G. A. (1998) Mania and ADHD: comorbidity or confusion. Journal of Affective Disorders, $\mathbf{5 1}$ 177-187.

CASTELLANOS, F. X. \& TANNOCK, R. (2002) Neuroscience of attentiondeficit/hyperactivity disorder: the search for endophenotypes. Nature Reviews Neuroscience, 3, 617-628.

COGHILL, D., NIGG, J., ROTHENBERGER, A., et al (2005) Whither causal models in the neuroscience of $A D H D$ ? Developmental Science, 8, 105-114.

FARAONE, S.V. \& DOYLE, A. E. (2000) Genetic influence on attention deficit hyperactivity disorder. Current Psychiatry Reports, 2, 143-146. FARAONE, S.V., BIEDERMAN, J. \& MILBERGER, S. (1995) How reliable are maternal reports of their children's psychopathology? One-year recall of psychiatric diagnoses of ADHD children. Journal of the American Academy of Child and Adolescent Psychiatry, 34 1001-1008.

FISCHER, M., BARKLEY, R. A., EDELBROCK, C. S., et al (1990) The adolescent outcome of hyperactive children diagnosed by research criteria: . Academic, attentional, and 
neuropsychological status. Journal of Consulting and Clinical Psychology, 58 580-588.

GOTTESMAN, I. I. \& GOULD,T. D. (2003) The endophenotype concept in psychiatry: etymology and strategic intentions. American Journal of Psychiatry, 160, 636-645.

HUSS, M. \& LEHMKUHL, U. (2002) Methylphenidate and substance abuse: a review of pharmacology, animal, and clinical studies. Journal of Attention Disorders, 6, S65-S71.

JADAD, A. R., BOOKER, L., GAULD, M., et al (1999) The treatment of attention deficit hyperactivity disorder: an annotated bibliography and critical appraisal of published systematic reviews and metaanalyses. Canadian Journal of Psychiatry, 44, 1025-1035. KREPPNER, J. M., O'CONNOR, T. G. \& RUTTER, M. (2001) Can inattention / overactivity be an institutional deprivation syndrome? Journal of Abnormal Child Psychology, 29 513-528.

KUPFER, D. J., BALTIMORE, R. S., BERRY, D. A., et al (2000) National Institutes of Health Consensus Development Conference Statement: Diagnosis and treatment of attention-deficit/ hyperactivity disorder (ADHD). Journal of the American Academy of Child and Adolescent Psychiatry, 39, 182-193.

LAHEY, B. B., APPLEGATE, B., MCBURNETT, K., et al (1994) DSM-IV field trials for attention deficit hyperactivity disorder in children and adolescents. American Journal of Psychiatry, 151, 1673-1685.
MILBERGER, S., BIEDERMAN, J.,

FARAONE, S.V., et al (1997) Associations between ADHD and psychoactive substance use disorders. Findings from a longitudinal study of high-risk siblings of ADHD children. American Journal of Addiction, 6 $318-329$.

NATIONAL INSTITUTE FOR CLINICAL EXCELLENCE (2000) Guidance on the Use of Methylphenidate (Ritalin Equasym) forAttention Deficit/ Hyperactivity Disorder (ADHD) in Childhood. London: National Institute for Clinical Excellence.

NIGG, J.T., WILLCUTT, E. G., DOYLE, A. E., et al (2005) Causal heterogeneity in attention-deficit hyperactivity disorder: do we need neuropsychologically impaired subtypes? Biological Psychiatry, 57, 1224-1230

PHILP, A.V., WATSON, L. \& MUIR, R (2002) Mental Health in Scotland: Information Soucres and Selected Highlights, Edinburgh: NHS Scotland Information and Statistics Division.

RHODES, S. M., COGHILL, D. R. \& MATTHEWS, K. (2004) Methylphenidate restores visual memory, but not working memory function in attention deficithyperkinetic disorder.

Psychopharmacology, 175 319-330.

ROBINS, E. \& GUZE, S. B. (1970) Establishment of diagnostic validity in psychiatric illness: its application to schizophrenia. American Journal of Psychiatry, 126, 983-987.
SCHACHAR, R. \& TANNOCK, R. (2002)

Syndromes of hyperactivity and

attention deficit. In Child and

Adolescent Psychiatry (eds M. Rutter \& effects in hyperactive children. Journal

E. Taylor), pp. 399-418. Oxford: Blackwell Science.

SCOTTISH INTERCOLLEGIATE GUIDELINES NETWORK (2001)

Attention Deficit and Hyperkinetic Disorders in Children and Young People: A National Clinical Guideline. Edinburgh: Scottish Intercollegiate Guidelines Network.

SHAFFER, D., GOULD, M. S., BRASIE, J. et al (1983) A Children's Global Assessment Scale (CGAS). Archives of General Psychiatry, 40, 1228-1231.

SOLANTO, M. V., ARNSTEN, A. F. \& CASTELLANOS, F. X. (2001) Stimulant Drugs and ADHD: Basic and Clinical Neuroscience. NewYork: Oxford University Press

SONUGA-BARKE, E. J. (2003) The dual pathway model of $A D / H D$ : an elaboration of neuro-developmental characteristics. Neuroscience and Biobehavioural Reviews, 27, 593-604.

SWANSON, J., GUPTA, S., GUINTA, D., et al (1999) Acute tolerance to methylphenidate in the treatment of attention deficit hyperactivity disorder in children. Clinical Pharmacology \& Therapeutics, 66, 295-305.

, R., SCHACHAR, R. \& LOGAN, C. (1995) Methylphenidate and cognitive flexibility: dissociated dose of Abnormal Child Psychology, 23, 235-266.

TAYLOR, E., CHADWICK, O., HEPTINSTALL, E., et al (1996) Hyperactivity and conduct problems as risk factors for adolescent development. Journal of the American Academy of Child and Adolescent Psychiatry, 35, 1213-1226.

TAYLOR, E., DOPFNER, M., SERGEANT, J., et al (2005) Clinical guidelines for hyperkinetic disorder - first upgrade. European Child and Adolescent Psychiatry, 13 (suppl. 1), 17-30.

VOLKOW, N. D. \& SWANSON, J. M. (2003) Variables that affect the clinical use and abuse of methylphenidate in the treatment of ADHD. American Journal of Psychiatry, 160, 1909-1918. VOLKOW, N. D. WANG, G. FOWLER, J. S., et al (2001) Therapeutic doses of oral methylphenidate significantly increase extracellular dopamine in the human brain. Journal of Neuroscience, 21, RC121.

WORLD HEALTH ORGANIZATION (1993) The ICD-10 Classification of Mental and Behavioural Disorders: Diagnostic Criteria for Research. Geneva:WHO

Dave Coghill Senior Lecturer and Honorary Consultant Child and Adolescent Psychiatrist, Division of Pathology and Neuroscience, Section of Psychiatry, University of Dundee, Ninewells Hospital and Medical School, Dundee DD1 9SR, e-mail: david.coghill@tpct.scot.nhs.uk 